\section{Primary prevention of SCD with ICD in the elderly}

\author{
Fabio Maria Gemelli*, Lucia Mancinelli, Olga Protic, Lorenzo \\ Pimpini and Roberto Antonicelli
}

UO Cardiology/UTIC/Telemedicine, INRCA Hospital of Ancona, Italy

\section{Introduction}

Implantable cardioverter defibrillators (ICDs) are electronic devices that can prevent sudden cardiac death (SCD) caused by arrhythmic events in patients.

The latest ESC/EAS and ACC/AHA Guidelines deem the placement of an ICDs appropriate in patients with heart failure class NYHA II and III in the presence of an ejection fraction less than or equal to $35 \%[1,2]$. ICDs are usually not indicated in either class I or IV patients. The Guidelines recommendations for primary prevention of SCD with ICD implantation do not take into account the age of the patients but only their life expectancy which must be at least 1 year.

Our patients usually are over eighty years old with heart failure and severely reduced ejection fraction. We must consequently decide if it is right to implant these patients with an ICD. Is the use of ICD in the patients over 80, in particular over 90 years old, really make sense becomes particularly important considering demographic changes that await us in the coming decades.

\section{Demographic considerations}

In the last decades, there has been a progressive change in the worldwide population, called "demographic transition." It is characterized by the transition from a traditional demographic regime to a modern demographic regime characterized by low levels of both births and deaths. It is based on high levels of both birth rates and mortality, especially for children [3] (Figure 1).

It is more evident in developing countries and is associated with the progressive aging of the population. In particular, Italy is involved in this change and represents one of the longest-lived populations with better health status [4]. In indeed, in 1863 the median age of death in Italy was 49.29 years, in 1901 it was 62,46 years and in 1951 it was 71.11 years (ISTAT data 2007). Today the life expectancy at birth is 80.8 years for men and 85.2 for women. According to the

\author{
More Information \\ *Address for Correspondence: Fabio Maria \\ Gemelli, Department of Medicine, The Italian \\ Research Center on Aging, Italy, Ancona 60127, \\ via della Montagnola 81, Tel: +393336447225 \\ Email: fabogemelli@yahoo.it; \\ fabio.gemelli@inrca.it \\ Submitted: 27 February 2020 \\ Approved: 28 March 2020 \\ Published: 30 March 2020 \\ How to cite this article: Gemelli FM, Mancinelli \\ L, Protic O, Pimpini L, Antonicelli R. Primary \\ prevention of SCD with ICD in the elderly. J \\ Cardiol Cardiovasc Med. 2020; 5: 067-072. \\ DOI: 10.29328/journal.jccm.1001089 \\ Copyright: (c) 2020 Gemelli FM, et al. This is \\ an open access article distributed under the \\ Creative Commons Attribution License, which \\ permits unrestricted use, distribution, and re- \\ production in any medium, provided the original \\ work is properly cited. \\ Check for updates \\ OPEN ACCESS
}

annual report of the Institute of Statistics, currently, there are almost fifteen thousand over 100 people in Italy. The aging of the population is certainly due to medical progress as well as researches and to the diffusion of healthy lifestyles and habits (e.g. sport, cultural participation) that influences improvement of health status. Nevertheless, because of these changes, the incidence of chronic diseases is increased. In particular, it is increasing the prevalence of heart failure and ventricular dysfunction and the first causes of death in older people are cardio-circulatory diseases, following by cancers. Moreover, the burden of electrophysiological disease in elderly patients is continuously rising. Atrial fibrillation and sick sinus syndrome are regarded as "geriatric conditions" and ventricular arrhythmias in failing hearts affect a large number of older people [5]. To treat, life threatening arrhythmias, the implantation of permanent pacemakers (PMK), ICDs and cardiac resynchronization therapy (CRT), are increased in the last decades. Decision about if device-based therapy is necessary in older people (over eighty years, in particular over ninety years) remains particularly challenging. Indeed, these therapies may influence the change in less morbidity and mortality in selected patients with heart failure and potential life-threatening arrhythmias (primary prevention). On the other hand, the complex comorbidity of many older patients makes-them more exposed to the risk of mortality and peri-procedural complications [6]. 

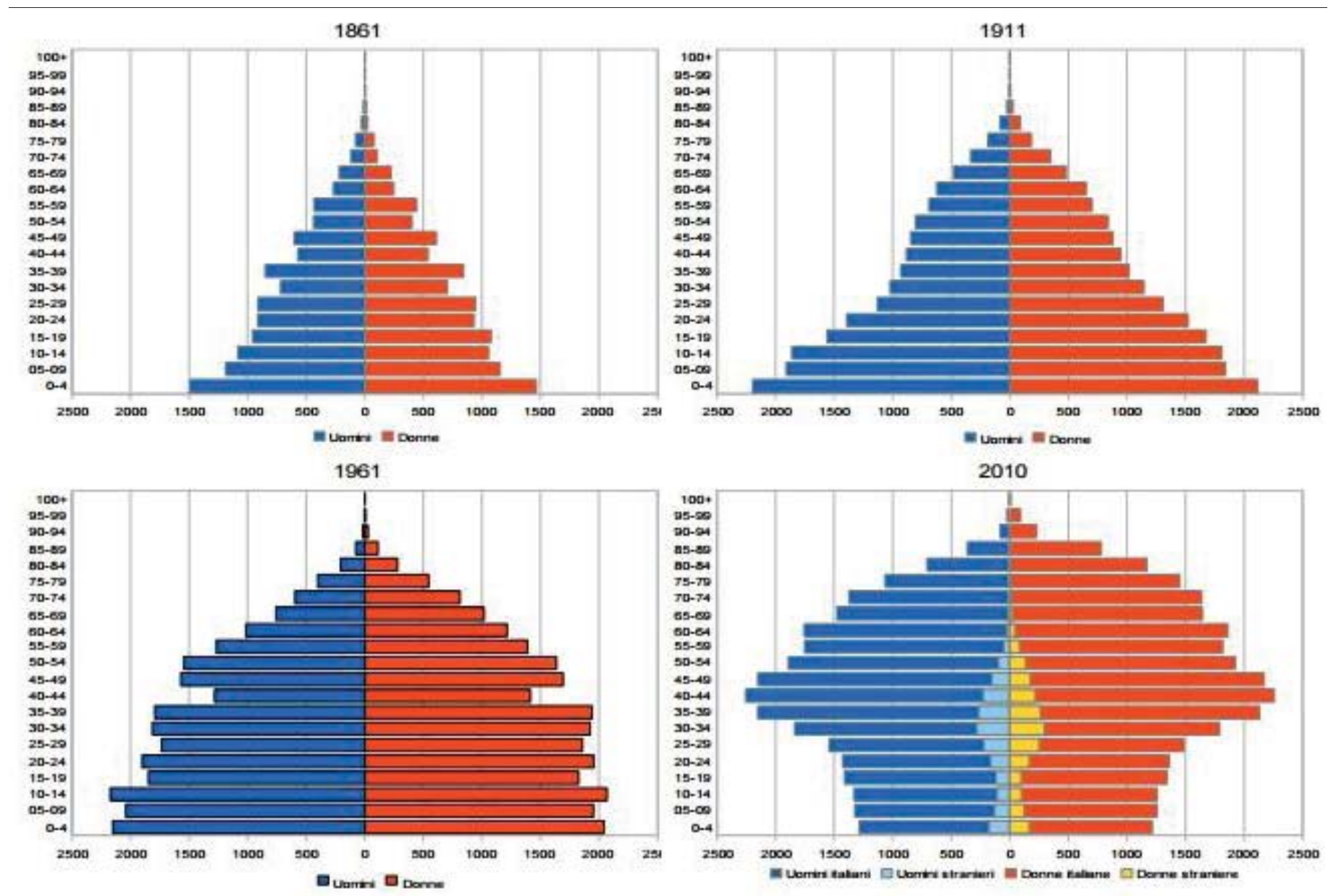

Figure 1: Demographic transition from 1861 to 2010. Istat data 2007.

\section{Ventricular arrhythmias and SCD in the elderly}

Premature ventricular beats (PVBs) are frequent in the elderly, and that is associated with a worse prognosis even in the absence of underlying cardiomyopathy [7]. The main causes of sustained ventricular arrhythmias in the elderly are ischaemic heart disease and dilated cardiomyopathy. In this setting of patients, frequent is an iatrogenic cause [8]. QT prolongation caused by neurological drugs or secondary to the use of antiarrhythmic drugs can lead to "torsades de pointe" which can result in SCD.

In older patients SCD may be caused mainly by malignant ventricular arrhythmias, monomorphic ventricular tachycardia (VT) or primary ventricular fibrillation (VF). In $17 \%$ cases, is secondary to bradycardia [9] and the primary cause is coronary artery disease. The elderly population has an increased incidence of SCD. The annual incidence in an 80 -year-old man is about 7 times greater than in a 40 -yearold man [20]. In women this trend is much more marked. The incidence of SDC in a woman over 70 is 40 times greater than in a 45-year-old woman [11]. However, in the elderly non-sudden death increases much more than SCD, so the consequent SCD/all-cause mortality ratio is progressively reduced with advancing age. This phenomenon is called "the paradox of SCD in the elderly" and derived by the fact that the elderly are a population with high baseline all-cause mortality risk in which comorbidities play an important role. In the presence of multiple and severe comorbidities the risk of nonsudden death is higher and this population may not benefit from the use of a device that reduces the risk of SCD.

\section{Evidence in favor of ICD in the elderly}

In ICD trials performed so far, the elderly, have been poorly researched. A relatively high number of elderly patients have been enrolled in the MADIT II trial, where about $20 \%$ of patients were over 75 years old [12]. A subgroup analysis of this study, Huang DT, demonstrated that elderly patients (204 patients aged more than 75 years) have the same reduction in mortality compared to younger patients (HR 0.56; 95\% C.I, $0.29-1.08$ vs HR 0.56; 95\% C.I, 0.29-1.08) [13]. However, the follow up in patients $\geq 75$ years was short (17.2 months) as well as patients $<75$ years old (20.8 months). Kong et al., in a meta-analysis including data from four trials on the use of ICD in primary prevention (MUST, MADIT-II, DEFINITE and SCD-HeFT), demonstrated that ICD use is effective in reducing all-cause mortality in patients $\geq 75$ years of age [14]. Chan, et 
al. in a prospective cohort of 965 patients with and without ischaemic cardiomyopathies ( $\mathrm{EF} \leq 35 \%$ ) significantly older than those in primary prevention trials, compared long-term mortality in patients who did and did not receive ICDs over a mean follow-up of $34 \pm 16$ months [15]. This study confirmed that the use of ICDs was associated with lower all-cause mortality among older patients and patients with a limited number of major co morbidities. under-represented. Moreover 45-day complications were not increased in elderly patients. Data from a registry of cardiac resynchronization therapydefibrillator (CRT-D) patients of the University of Pittsburgh, demonstrated, that mortality among CRT-D recipients $\geq 80$ years old is higher than in younger patients but isn't excessive [17]. Also the risk of inappropriate shocks in older patients is relatively low and significantly less than in younger patients suggesting that CRT-D should be given due consideration in elderly patients with heart failure (HF). Further confirmation that ICD implantation is safe in the elderly was a study of Al-Khatib, et al. that studied 8581 patients aged $\geq 65$ years who received and ICD [18]. In this study age was not an independent risk factor for increased complications after device implantation.

\section{Evidence against ICD in the elderly}

In the trials of primary prevention of SCD with ICD, MADITII and SCD-HeFT, the benefit of the device appears clear only in a mid- to long-term follow-up (2-5 years). Still, the median survival of elderly patients with an ICD in most studies that have been seen, is $<5$ years [19]. Therefore, the effectiveness of the ICD in extending life expectation seems marginal. A meta-analysis on pooled data from three trials (DEFINITE, SCD-HeFT and MADIT) do not demonstrate a significant survival benefit for the ICD in the elderly [20]. Fauchier, et al. in a French registry of 5534 primary prevention ICD recipients, demonstrated, that older age was independently associated with a higher rate of early complications and a lower rate of inappropriate therapies [21]. In the secondary prevention setting, a meta-analysis on pooled data from three trials (AVID, CIDS and CASH) documented that ICD implantation did not seem to determine a survival benefit in elderly patients [22]. The DANISH study that evaluated 1116 patients with non-ischemic systolic heart failure, did not demonstrated a benefit on all-cause mortality with ICD implantation. However, the subgroup analysis demonstrated a possible agedependent correlation between ICD utilization and mortality with survival benefit evident only in the youngest patients ( $\leq$ 70 years old) [23].

\section{Biological and chronological age and the concept of frailty}

There are two kinds of ages, chronological and biological. Chronological age is the number of years of one person has been alive. On the other hand, biological age refers to how old a person seems to be. The age, depends on our genetics, but also is impacted by external factors, including diet, exercise, stress, and smoking. Many gerontologists believe that chronological age does not consider these external factors. In the last decades, we have seen how the improvement of health status in older population increases the opportunity of implantation of PMK, ICDs and CRT. A part of these older patients can present complex comorbidity that makes this population more fragile. Thus, in frailty, there is a difficulty in determining risk-benefit trade-offs when these options are considered for older adults. It has become clear that age alone is insufficient to characterize these patients and determine their eligibility for device-based therapies [24]. The concept of frailty has emerged as a means of better characterizing the resiliency of older adults beyond their age and comorbidities to refine estimates of predicted risk and guide decisions for individualized care. Frailty is a condition, characterized by a loss of biological reserves, which leads to failure of homeostatic mechanisms following stressor events [25]. Frialty, is an emerging concept in modern healthcare due to its association with adverse health outcomes and frequent hospital admissions. The prevalence in hospitalized elderly patients it is estimated to be between $24.7 \%$ and $80 \%$. The variability is due to varying populations, definitions and diagnostic criteria [26]. In literature there are many pieces of evidences about the association between frailty and negative outcomes in chronic disease, especially in the cardio-vascular field. Indeed, frailty is correlated to the worst outcomes in patients affected by heart failure and acute coronary syndrome. Frailty is becoming an instrument more frequently used to decision-making in the therapeutic-diagnostic process in elderly patients suffering from specific pathologies. Frailty is certainly an independent predictor of non-response to CRT and a higher risk of hospitalization for HF and mortality [27]. On the other hand, there are few contrasting data regarding the association between frailty and device-based therapy [28]. No frailty index has yet been validated to assess a patient's eligibility for device implantation. Furthermore, there is a different conceptualization of frailty among older people from professional definitions of frailty, across physical, cognitive and social domains $\mathrm{T}$, they reject the application of the concept of frailty to themselves. They also highlight the importance of functional independence to maintain an acceptable quality of life [29]. A recent study shows that there is an agreement between patient-reported and physiciansassigned Clinical Frailty Score in "well" and mildly frail older people. The patient-reported Clinical Frailty Score is lower than that estimated by physicians in "managing-well" people and moderately and severely frail people [30]. Thus, there is discordance in less-frail patients. Finally, there are emerging data that shows that device-based therapies are associated with high levels of patient acceptability and satisfaction [31].

Importance of comorbidities in patients with indication to ICD

In elderly patients, both cardiac and extracardiac comorbidities are frequent. With regards to cardiac comorbidities, very important is heart failure (HF) that has a prevalence between $10 \%$ and $20 \%$ in subjects aged $70-80$ years 
and probably they have the same need for ICD or pacemaker implantation, even if life expectancy is short in these patients [32]. About $50 \%$ of HF patients have more than 75 years. In HF patients, 50\% present preserved ejection fraction HF. Sudden cardiac death affects 6 to 9 times more frequently in HF patients than in the general population [33].

Diabetes mellitus (DM) is an important independent predictor of morbidity and mortality [34]. However, diabetic patients have the same benefit from ICD therapy as nondiabetic patients, even if they are sicker and they can have a higher mortality rate overall [35]. Moreover, DM is not a predictor of inadequate response to CRT, and diabetic HF patients treated with CRT have similar prognosis as nondiabetic HF patients [36].

The prevalence of atrial fibrillation (AF) increases significantly with age and as the NYHA class increases, it pass from the $5 \%$ of NYHA 1 to $40 \%$ of NYHA IV in patients with $\mathrm{HF}$ [37]. AF is associated with a higher risk of cardiac events and mortality. AF, per se, do not change the indication to use a device in elderly patients, while, it can influence the choice of the device and its mode of operation. Van Boven, et al. showed that in patients treated with CRT-D, AF is an independent risk factor, not only for mortality, but also for appropriate and inappropriate shocks [38].

Chronic kidney disease (CKD) is a severe condition associated with high morbidity and mortality and a decrease in quality of life. SCD is more frequent in patients with CKD and remains one of the primary causes of death among these vulnerable patients [39]. Bansal, et al. in a large cohort of patients who underwent primary prevention ICD implantation, do not found evidence that rates of shocks and ATP therapy were different among those with and without CKD. These results suggest that potential concerns for more frequent or inappropriate ICD therapies should not preclude appropriate primary prevention ICD implantation among patients with CKD who are known to be at high risk for SCD [40].

It follows that older patients with comorbidities and with a reasonable expectation of survival, may have an improvement in their prognosis from the use of devices like ICDs and CRT. The problem is that it is difficult to standardized criteria for define good life expectancy. Some authors have tried to create risk scores to predict mortality in ICD recipients [41].

\section{Risk scores}

Many risk stratification scores have been created to estimate the risk of patients that can receive an ICD involving different parameters.

Goldenberg et al., in a MADIT-II sub-study, developed a simple risk stratification score for primary therapy with ICD [42]. They stratified the patients allocated in the conventional therapy arm according to the presence of five easy clinical parameters such as age $>70$ years, NYHA $>$ II, blood urea nitrogen $(\mathrm{BUN})>26 \mathrm{mg} / \mathrm{dl}, \mathrm{QRS}>120 \mathrm{msec}$ and atrial fibrillation. The study suggests a U-shaped pattern for ICD efficacy, with evident benefit in intermediate-risk patients and reduced efficiency in lower- and higher-risk subsets. Anné, et al. validated this risk score in a cohort of elderly patients [43]. The authors retrospectively analysed all clinical and survival data of 179 patients $\geq 75$ years with an ICD. The mortality of the cohort was compared with ICD patients aged 60-70 years originating from the same database and to an age- and a sex-matched cohort of Dutch persons. Survival was worse in elderly patients than younger patients and in the age- and sex-matched group of elderly persons. However, survival was not significantly worse when comparing elderly ICD patients without additional risk factors to the general population.

Another risk score, defined SHOCKED, is based on the analysis of data from more than 45.000 primary prevention ICD patients [44].The authors studied a development cohort and validation cohort of Medicare beneficiaries receiving ICD and evaluated death prediction within 4 years from ICD implantation. About $40 \%$ of these patients were $\geq 75$ years of age. The model was based on 7 clinically relevant predictors of mortality identified from complete model results: $\geq 75$ years of age, NYHA III, atrial fibrillation, chronic obstructive pulmonary disease, chronic kidney disease, LVEF $\leq 20 \%$, and diabetes mellitus. This model accurately identifies patients at highest risk for death after device implantation.

Another algorithm was developed by Kraaier, et al. that studied 861 prophylactic recipients with ischaemic or non-ischaemic dilated cardiomyopathy (DCM) [43]. Four clinical parameters were considered: age $\geq 75$ years, LVEF $\leq$ $20 \%$, history of atrial fibrillation and estimated glomerular filtration rate $($ GFR $) \leq 30 \mathrm{~mL} / \mathrm{min} / 1.73 \mathrm{~m}^{2}$. The co-presence of these factors influenced the mortality of the patients, and this data, subsequently, was validated in 706 primary prevention patients [45].

Chong, et al. demonstrated that clinical comorbidities (liver or respiratory or renal dysfunction, anaemia, prior cerebral vascular injury) act synergistically to increase mortality risk. Patients with clinical markers involving $\geq 2$ organ systems had a 38\% 1-year mortality rate despite the ICD implantation [46].

\section{Conclusion}

The researches we have described in this review could assist in our understanding of current recommendations that only elderly patients with a reasonable expectation of survival, with good functional status for one year, should receive ICDs. As there is no standardization of a 'reasonable expectation of survival, physicians generally rely on their clinical judgment. To quantify the impact of a specific organ dysfunction on survival, it is necessary to use a multidisciplinary assessment. Elderly patients that still have a discrete survival probability 
could be the target of ICD implantation, in particular when there are no additional clinical risk factors. The presence or absence of additional clinical risk factors should be considered when deciding to implant an ICD since they strongly correlate with survival. The use of a risk score can help physicians when deciding if the patient needs to be addressed to ICD implantation.

\section{References}

1. Ponikowski P, Voors AA, Anker SD, Bueno H, Cleland JGF, et al. 2016 ESC Guidelines for the diagnosis and treatment of acute and chronic heart failure: The Task Force for the diagnosis and treatment of acute and chronic heart failure of the European Society of Cardiology (ESC). Developed with the special contribution of the Heart Failure Association (HFA) of the ESC. Eur Heart J. 2016; 37: 2129-2200.

PubMed: https://www.ncbi.nlm.nih.gov/pubmed/27206819

2. Yancy CW, Jessup M, Bozkurt B, Butler J, Casey DE Jr, et al. 2013 ACCF/AHA Guideline for the Management of Heart Failure. A report of the American College of Cardiology Foundation/American Heart Association Task Force on Practice Guidelines. Circulation. 2013; 128 : e240-e327.

PubMed: https://www.ncbi.nlm.nih.gov/pubmed/23747642

3. Kirk D. Demographic transition theory. Popul Stud (Camb). 1996; 50: 361-387.

PubMed: https://www.ncbi.nlm.nih.gov/pubmed/11618374

4. VII Rapporto RBM - Censis sulla Sanità Pubblica, Privata e Intermediata. Luglio 2017.

5. Bibas L, Levi M, Touchette J, Mardigyan V, Bernier M, et al. Implications of Frailty in Elderly Patients With Electrophysiological Conditions. JACC Clin Electrophysiol. 2016; 2: 288-294.

PubMed: https://www.ncbi.nlm.nih.gov/pubmed/29766886

6. Chen MY, Orkaby AR, Rosenberg MA, Driver JA. Frailty, Implantable Cardioverter Defibrillators, and Mortality: A Systematic Review. J Gen Intern Med. 2019; 34: 2224-2231.

PubMed: https://www.ncbi.nlm.nih.gov/pubmed/31264082

7. Sherman H, Sandberg S, Fineberg HV. Exponential increase in agespecific prevalence of ventricular dysrhythmia among males. J Chronic Dis. 1982; 35: 743-750.

PubMed: https://www.ncbi.nlm.nih.gov/pubmed/6179958

8. Raybaud F, Camous JP, Tibi T, Baudouy M, Morand P. Severe arrhythmias in the elderly: a prospective hospital study. Arch Mal Coeur Vaiss. 1995; 88: 27-33.

PubMed: https://www.ncbi.nlm.nih.gov/pubmed/7646246

9. Rubart M, Zipes DP. Mechanisms of sudden cardiac death. J Clin Invest. 2005; 115: 2305-2315.

PubMed: https://www.ncbi.nlm.nih.gov/pubmed/16138184

10. Yung D, Birnie D, Dorian P, Healey JS, Simpson CS, et al. Survival after implantable cardioverter-defibrillator implantation in the elderly. Circulation. 2013; 127: 2383-2392.

PubMed: https://www.ncbi.nlm.nih.gov/pubmed/23775193

11. Chugh SS1, Jui J, Gunson K, Stecker EC, John BT, et al. Current burden of sudden cardiac death: multiple source surveillance versus retrospective death certificate-based review in a large US community. J Am Coll Cardiol. 2004; 44: 1268-1275.

PubMed: https://www.ncbi.nlm.nih.gov/pubmed/15364331

12. Moss AJ, Zareba W, Hall WJ, Klein H, Wilber DJ, et al. Prophylactic implantation of a defibrillator in patients with myocardial infarction and reduced ejection fraction. N Engl J Med. 2002; 346: 877-883.

PubMed: https://www.ncbi.nlm.nih.gov/pubmed/11907286
13. Huang DT, Sesselberg HW, McNitt S, Noyes $K$, Andrews $M L_{\text {, }}$ et al. Improved survival associated with prophylactic implantable defibrillators in elderly patients with prior myocardial infarction and depressed ventricular function: a MADIT-II sub study. J Cardiovasc Electrophysiol. 2007; 18: 833-838.

PubMed: https://www.ncbi.nlm.nih.gov/pubmed/17537209

14. Kong MH, Al-Kathib SM, Sanders GD, Hasselbland V, Peterson ED. Use of implantable cardioverter-defibrillators for primary prevention in older patients: a systematic literature review and meta-analysis. Cardiol J. 2011; 18: 503-514.

PubMed: https://www.ncbi.nlm.nih.gov/pubmed/21947985

15. Chan PS, Nallamothu BK, Spertus JA, Masoudi FA, Bartone C, et al. Impact of age and medical comorbidity on the effectiveness of implantable cardioverter-defibrillators for primary prevention. Circ Cardiovasc Qual Outcomes. 2009; 2: 16-24.

PubMed: https://www.ncbi.nlm.nih.gov/pubmed/20031808

16. Yung D, Birnie D, Dorian P, Healey JS, Simpson CS, et al. Survival after implantable cardioverter-defibrillator implantation in the elderly. Circulation. 2013; 127: 2383-2392.

PubMed: https://www.ncbi.nlm.nih.gov/pubmed/23775193

17. Adelstein EC, Liu J, Jain S, Schwartzman D, Althouse AD, et al. Clinical outcomes in cardiac resynchronization therapy-defibrillator recipients 80 years of age and older. Europace. 2016; 18: 420-427.

PubMed: https://www.ncbi.nlm.nih.gov/pubmed/26487669

18. Al-Khatib SM, Greiner MA, Peterson ED, Hernandez AF, Schulman $\mathrm{KA}$, et al. Patient and implanting physician factors associated with mortality and complications after implantable cardioverter-defibrillator implantation, 2002-2005. Circ Arrhythmia Electrophysiol. 2008; 1: 240149.

PubMed: https://www.ncbi.nlm.nih.gov/pubmed/19169382

19. Bardy GH, Lee KL, Mark DB, Poole JE, Packer DL, et al. Amiodarone or an implantable cardioverter defibrillator for congestive heart failure. $\mathrm{N}$ Engl J Med. 2005; 352: 225-2237.

PubMed: https://www.ncbi.nlm.nih.gov/pubmed/15659722

20. Santangeli P, Di Biase L, Dello Russo A, Casella M, Bartoletti S, et al Meta-analysis: age and effectiveness of prophylactic implantable cardioverter defibrillators. Ann Intern Med. 2010; 153: 592-599. PubMed: https://www.ncbi.nlm.nih.gov/pubmed/21041579

21. Fauchier L, Marijon E, Defaye $P$, Piot $O$, Sadoul N, et al. Effect of age on survival and causes of death after primary prevention implantable cardioverter defibrillator implantation. Am J Cardiol. 2015; 115: 14151422.

PubMed: https://www.ncbi.nlm.nih.gov/pubmed/25784518

22. Healey JS, Hallstrom AP, Kuck KH, Nair G, Schron EP, et al. Role of implantable defibrillator among elderly patients with a history of lifethreatening ventricular arrhythmias. Eur Heart J. 2007; 28: 1746-1749. PubMed: https://www.ncbi.nlm.nih.gov/pubmed/17283003

23. Elming MB, Nielsen JC, Haarbo J, Videbæk L, Korup E, et al. Age and Outcomes of Primary Prevention Implantable CardioverterDefibrillators in Patients with Nonischemic Systolic Heart Failure. Circulation. 2017; 136: 1772-1780.

PubMed: https://www.ncbi.nlm.nih.gov/pubmed/28877914

24. Manian U, Gula LJ. Arrhythmia Management in the Elderly-Implanted Cardioverter Defibrillators and Prevention of Sudden Death. Can J Cardiol. 2016; 32: 1117-1123.

PubMed: https://www.ncbi.nlm.nih.gov/pubmed/27568872

25. Clegg A, Young J, Iliffe S, Rikkert MO and Rockwood K. Frailty in elderly people. Lancet. 2013; 381: 752-62.

PubMed: https://www.ncbi.nlm.nih.gov/pubmed/23395245

26. Andela RM, Dijkstra A, Slaets JP, Sanderman R. Prevalence of frailty on clinical wards: description and implications. Int J Nurs Pract. 2010; 16 : 
14-19. Epub 2010/02/18.

PubMed: https://www.ncbi.nlm.nih.gov/pubmed/20158543

27. Kubala M, Guédon-Moreau L, Anselme F, Klug D, Bertaina G, et al Utility of Frailty Assessment for Elderly Patients Undergoing Cardiac Resynchronization Therapy. JACC Clin Electrophysiol. 2017; 3: 15231533.

PubMed: https://www.ncbi.nlm.nih.gov/pubmed/29759834

28. Setoguchi S, Warner Stevenson L, Stewart GC, Bhatt DL, Epstein $A E$, et al. Influence of healthy candidate bias in assessing clinical effectiveness for implantable cardioverter-defibrillators: cohort study of older patients with heart failure. BMJ. 2014; 8: 348: g2866.

PubMed: https://www.ncbi.nlm.nih.gov/pubmed/24812112

29. Warmoth K, Lang IA, Phoenix C. "Thinking you're old and frail": a qualitative study of frailty in older adults. Ageing Soc. 2016; 36: 1483-500.

30. Dresden SM, Platts-Mills TF, Kandasamy D, Walden L, Betz ME. Patient versus Physician Perceptions of Frailty: A comparison of Clinical Frailty Scale Scores of Older Adults in the Emergency Departement. Acad Emerg Med. 2019; 26: 1089-1092.

PubMed: https://www.ncbi.nlm.nih.gov/pubmed/31265194

31. Datino T, Miracle Blanco Á, Núñez García A, González-Torrecilla E, Atienza Fernández $\mathrm{F}$, et al. Safety outpatient implantation of the implantable cardioverter-defibrillator. Rev Esp Cardiol. 2015; 68: 579-584.

PubMed: https://www.ncbi.nlm.nih.gov/pubmed/25435093

32. McMurray JJ1, Adamopoulos S, Anker SD, Auricchio A, Böhm M, et al. ESC Guidelines for the diagnosis and treatment of acute and chronic heart failure 2012: the task force for the diagnosis and treatment of acute and chronic heart failure 2012 of the ESC. Developed in collaboration with HFA of the ESC. Eur Heart J. 2012; 33: 1787-1847. PubMed: https://www.ncbi.nlm.nih.gov/pubmed/22611136

33. Azad N, Kathiravelu A, Minoosepeher S, Herbert P, Fergusson D. Gender difference in the aetiology of heart failure: a systematic review. J Geriatr Cardiol. 2011; 8: 15-23.

PubMed: https://www.ncbi.nlm.nih.gov/pubmed/22783280

34. Moghissi ES, Korytkowski MT, DiNardo M, Einhorn D, Hellman R, et al. American Association of Clinical Endocrinologists; American Diabetes Association. American Association of Clinical Endocrinologists and American Diabetes Association consensus statement on inpatient glycemic control. Diabetes Care. 2009; 32: 1119-1131.

PubMed: https://www.ncbi.nlm.nih.gov/pubmed/19429873

35. Wittenberg SM, Cook JR, Hall WJ, McNitt S, Zareba W, et al. Comparison of efficacy of implanted cardioverter defibrillator in patients with versus without diabetes mellitus. Am J Cardiol. 2005; 96: 417-419. PubMed: https://www.ncbi.nlm.nih.gov/pubmed/16054472

36. Fantoni C, Regoli F, Ghanem A, Raffa S, Klersy C, et al. Long-term outcome in diabetic heart failure patients treated with cardiac resynchronization therapy. Eur J Heart Fail. 2008; 10: 298-307. PubMed: https://www.ncbi.nlm.nih.gov/pubmed/18296111
37. Maisel WH, Stevenson LW. Atrial fibrillation in heart failure: epidemiology, pathophysiology, and rationale for therapy. Am J Cardiol. 2003; 91: 2D-8D.

PubMed: https://www.ncbi.nlm.nih.gov/pubmed/12670636

38. van Boven N, Theuns D, Bogaard K, Ruiter J, Kimman G, et al. Atrial fibrillation in cardiac resynchronization therapy with a defibrillator: a risk factor for mortality, appropriate and inappropriate shocks. J Cardiovasc Electrophysiol. 2013; 24: 1116-1122.

PubMed: https://www.ncbi.nlm.nih.gov/pubmed/23889733

39. Deo R, Sotoodehnia N, Katz R, Sarnak MJ, Fried LF, et al. Cystatin C and sudden cardiac death risk in the elderly. Circ Cardiovasc Qual Outcomes. 2010; 3: 159-164.

PubMed: https://www.ncbi.nlm.nih.gov/pubmed/20233980

40. Bansal N, Szpiro A, Masoudi F, Greenlee RT, Smith DH, et al. Kidney function and appropriateness of device therapies in adults with implantable cardioverter defibrillators. Heart. 2017; 103: 529-537. PubMed: https://www.ncbi.nlm.nih.gov/pubmed/27742796

41. Kubala M, Guédon-Moreau L, Anselme F, Klug D, Bertaina G, et al. Utility of Frailty Assessment for Elederly Patients Undergoing Cardiac Resynchronization Therapy. JACC Clin Electrophysiol. 2017 Dec 26; 30: 1523-1533.

PubMed: https://www.ncbi.nlm.nih.gov/pubmed/29759834

42. Goldenberg I, Vyas AK, Hall WJ, Moss AJ, Wang H, et al. Risk stratification for primary implantation of a cardioverter-defibrillator in patients with ischaemic left ventricular dysfunction. J Am Coll Cardiol. 2008; 51: 288-296.

PubMed: https://www.ncbi.nlm.nih.gov/pubmed/18206738

43. Anné $W$, Schaer B, Van Belle $Y$, Szili-Torok T, Smith T, et al. ICDs at higher age and clinical risk factors. Neth Heart J. 2014; 22: 279-285. PubMed: https://www.ncbi.nlm.nih.gov/pubmed/24795210

44. Bilchick KC, Stukenborg GJ, Kamath S, Cheng A. Prediction of mortality in clinical practice for medicare patients undergoing defibrillator implantation for primary prevention of sudden cardiac death. J Am Coll Cardiol. 2012; 60: 1647-1655.

PubMed: https://www.ncbi.nlm.nih.gov/pubmed/23021331

45. Kraier K, Scholten MF, Tijssen JG, Theuns DA, Jordaens LJ, et al. Early mortality in prophylactic implantable cardioverter-defibrillator recipients: development and validation of a clinical risk score. Europace. 2014;16: 40-46.

PubMed: https://www.ncbi.nlm.nih.gov/pubmed/23918791

46. Chong D, Tan BY, Ho KL, Liew R, Teo WS, et al. Clinical markers of organ dysfunction associated with increased 1-year mortality postimplantable cardioverter defibrillator implantation. Europace. 2013; 15: 508-514.

PubMed: https://www.ncbi.nlm.nih.gov/pubmed/22848076 